\title{
Expression and function of the ACE2/angiotensin(1-7)/Mas axis in osteosarcoma cell lines U-2 OS and MNNG-HOS
}

\author{
STEPHAN ALBRECHT ENDER ${ }^{1}$, ANDREA DALLMER ${ }^{2}$, FLORIAN LÄSSIG ${ }^{2}$, \\ UWE LENDECKEL $^{2}$ and CARMEN WOLKE ${ }^{2}$ \\ ${ }^{1}$ Department of Orthopaedics and Orthopaedic Surgery; ${ }^{2}$ Institute of Medical Biochemistry and Molecular Biology, \\ University Medicine Greifswald, Sauerbruchstrasse, Greifswald D-17475, Germany
}

Received September 24, 2013; Accepted March 24, 2014

DOI: $10.3892 / \mathrm{mmr} .2014 .2266$

\begin{abstract}
The renin-angiotensin-system(RAS), via its classical angiotensin-converting enzyme (ACE)/angiotensin II/angiotensin II type 1 receptor (AT1R)-axis, is associated with proliferation and metastasis of numerous types of solid tumor. AT1R blockers reduce tumor volume and decrease liver and lung metastasis in murine models of osteosarcoma. Expression and function of the alternative ACE2/Ang(1-7)/Mas axis in osteosarcoma is yet to be studied. In the present study, the basic and interleukin (IL)-1 $\beta$-stimulated expression of components of this alternative RAS axis were analyzed and the impact of Mas on proliferation and/or migration of U-2 OS and MNNG-HOS osteosarcoma cells was studied. Quantitative polymerase chain reaction revealed that the two cell lines expressed the Ang(1-7)-generating peptidases ACE2, neutral endopeptidase 24.11 and prolyl-endopeptidase together with the putative receptor for Ang(1-7), Mas. IL-1 $\beta$ provoked an induction of Mas mRNA and protein expression which was associated with a reduction of proliferation and migration. By contrast, small interfering RNA-mediated knockdown of Mas expression led to increased cell proliferation. In conclusion, osteosarcoma cells express a functional active alternative ACE2/Ang(1-7)/Mas axis. The induction and reinforcement of this axis may be beneficial for the treatment of osteosarcoma by reducing growth and preventing cancer metastasis. These effects may be achieved directly by the administration of Mas agonists or, indirectly, via blocking the classical AngII RAS axis via ACE inhibitors or AT1R antagonists.
\end{abstract}

Correspondence to: Dr Carmen Wolke, Institute of Medical Biochemistry and Molecular Biology, University Medicine Greifswald, DZ 7 Ferdinand-Sauerbruch-Strasse, Greifswald D-17475, Germany

E-mail: carmen.wolke@uni-greifswald.de

Key words: osteosarcoma, renin-angiotensin-system, angiotensin(1-7), Mas, U-2 OS, MNNG-HOS

\section{Introduction}

The renin-angiotensin-system (RAS) consists of different axes and has been associated with a broad variety of physiological and pathophysiological processes. Angiotensin II (AngII) is the major effector peptide of the classical RAS axis which is best known for its role in systemic volume homeostasis and blood pressure control (1). AngII is generated from AngI by angiotensin-converting enzyme (ACE) and via binding to its preferred type 1 receptor, AT1R, affects important processes, including proliferation, apoptosis, fibrosis and inflammation (2). The classical RAS has also been implicated in tumorigenesis (2), in part due to its strong angiogenic activity mediated by the AngII/AT1R-dependent (3) induction of proangiogenic factors, including vascular endothelial growth factor (VEGF) (4), angiopoietin 2 (5) and platelet-derived growth factor (PDGF) (6). In ovarian carcinoma, invasion and angiogenesis are correlated to AT1R expression levels (7). Accordingly, ACE-inhibitors have been demonstrated to suppress the growth and angiogenic activity of head and neck carcinoma (8). In another study, ACE-inhibition and blockade of AT1R reduced liver metastasis and angiogenesis in a mouse model of colorectal carcinoma (9). The ACE insertion/deletion polymorphism (ACE I/D), and specifically the DD-genotype, has also been linked to the development of early gastric cancer (10) and has been associated with increased lymph node metastasis (11). The AT1R expression status and ACE I/D are independent risk factors for nodal spread in intestinal type gastric cancer (12). For osteosarcoma, a recent study demonstrated a reduction in tumor growth and lung and liver metastasis by application of the AT1R antagonist, CV11974, in a murine osteosarcoma model (13).

The non-classical, alternative ACE2/Ang(1-7)/Mas axis in numerous aspects acts as a negative modulator of AngII-mediated effects. In this axis, ACE2 facilitates the formation of Ang(1-7) which is the high affinity ligand for Mas (14). Ang(1-7) has been demonstrated to inhibit migration and invasion of lung cancer cells in vitro, possibly via the inhibition of p38 and c-Jun N-terminal kinase (15) as well as extracellular signal-regulated kinase 1/2 (16) MAP kinases. Accordingly, overexpression of the Ang(1-7)-generating ACE2 has been demonstrated to decrease proliferation, invasion and VEGF expression in lung cancer (17). A previous study demonstrated 
Table I. Primers used for quantitative polymerase chain reaction.

\begin{tabular}{|c|c|c|c|}
\hline Primer & Sequence $\left(5^{\prime}-3^{\prime}\right)$ & Size (bp) & Annealing temperature $\left({ }^{\circ} \mathrm{C}\right)$ \\
\hline h-ACE-DS & GCAGAATCTTGCTGGTCTCTG & 262 & 63 \\
\hline h-ACE-US & CTCAAGTACTTCCAGCCAGTC & & \\
\hline h-ACE2-DS & TCCAGTACTGTAGATGGTGC & 372 & 55 \\
\hline h-ACE2-US & СTCCTTCTCAGCCTTGTTGC & & \\
\hline h-APN-DS & GCTGAGGGTGTAGTTGAGCTTC & 319 & 62 \\
\hline h-APN-US & CATCGGACTGTCAGTGGTGTAC & & \\
\hline h-AT2R1-DS & CTGCATTCTACAGTCACGTATGATG & 416 & 62 \\
\hline h-AT2R1-US & CTTCGACGCACAATGCTTGTAGCC & & \\
\hline h-AT2R2-DS & GTAAATCAGCCACAGCGAGG & 214 & 62 \\
\hline h-AT2R2-US & GGGCTTGTGAACATCTCTGG & & \\
\hline h-IRAP-DS & GACCTGAAGAGCCTGAACTG & 340 & 58 \\
\hline h-IRAP-US & CAGTGCAACTGGTTACAGGC & & \\
\hline h-Mas1-DS & CAATGCCGACTGGTACTTG & 407 & 62 \\
\hline h-Mas1-US & ACATCTCACTGGCAGGAAC & & \\
\hline h-NEP-DS & GAGGTTCTCCACCTCTGCTATC & 331 & 58 \\
\hline h-NEP-US & GCACTCTATGCAACCTACGATG & & \\
\hline h-PEP-DS & CCAAGACATGGTAGTAGAGC & 300 & 63 \\
\hline h-PEP-US & CCAACTACTGTCTGACGATG & & \\
\hline h- $\alpha$-Tubulin-DS & CATTTCACCATCTGTTGGCTGGCTC & 528 & 58 \\
\hline$h-\alpha$-Tubulin-US & CACCCGTCTTCAGGGTTCTTGGTTT & & \\
\hline
\end{tabular}

ACE, angiotensin-converting enzyme; APN, alanyl-aminopeptidase; AT2R1/2, angiotensin II type 1/2 receptor; IRAP; insulin-regulated aminopeptidase; PEP, prolyl-endopeptidase; NEP, neutral endopeptidase 24.11; DS, downstream; US, upstream.

that ACE2 overexpression in A549 lung cancer cells reduced metastasis in vivo and increased the expression of E-cadherin in vivo and in vitro (18).

It is well established that in general, cancer cells use glucose as their predominant energy substrate $(19,20)$ and it has been recently demonstrated that glucose transporter 1 (GLUT1) is the main glucose transporter in osteosarcoma cells (21). Elevated glucose uptake as measured by fluorodeoxyglucose $(18 \mathrm{~F})$ uptake is associated with a poor prognosis in patients with osteosarcoma $(22,23)$. Of note, $\operatorname{Ang}(1-7)$ has been implicated in regulating glucose uptake into adipocytes and muscle and, therefore, contributes to glucose homeostasis $(24,25)$. Thus, the present study aimed to elucidate if the ACE2/Ang(1-7)/Mas axis of the RAS may also affect osteosarcoma cell proliferation.

\section{Materials and methods}

Cell culture. The osteosarcoma cell lines U-2 OS and MNNG-HOS were purchased from the American Type Culture Collection (ATCC, Manassas, VA, USA). U-2 OS cells were maintained in McCoy's 5A medium (PAA Laboratories GmbH, Linz, Austria) and MNNG-HOS in MEM with Earle's Salt (Gibco, Darmstadt, Germany) and supplemented with $10 \%$ fetal calf serum (PAA Laboratories, Cölbe, Germany), $2 \mathrm{mM}$ L-glutamine (PAA Laboratories), $1 \mathrm{mM}$ sodium pyruvate, $100 \mathrm{U} / \mathrm{ml}$ penicillin and $100 \mu \mathrm{g} / \mathrm{ml}$ streptomycin (PAA Laboratories, Pasching, Austria), at $37^{\circ} \mathrm{C}$ in a $5 \% \mathrm{CO}_{2}$ humidified atmosphere. All chemicals for the buffer preparation were obtained from Sigma-Aldrich (Steinheim, Germany). Other providers were named separately.

$R N A$ preparation and quantitative polymerase chain reaction ( $q P C R)$. For experiments to investigate the influence of interleukin (IL)-1 $\beta$ (PAN-Biotech GmbH, Aidenbach, Germany) and angiotensin (1-7; Bachem Distribution Services $\mathrm{GmbH}$, Weilam Rhein, Germany), the cells were seeded at a density of $5 \times 10^{5}$ cells/well in a six-well plate (Sarstedt, Nümbrecht, Germany) at a final volume of $3 \mathrm{ml}$ and incubated for $24 \mathrm{~h}$. RNA was prepared using innuPrep RNA Mini kit (Analytik Jena AG, Jena, Germany) according to the manufacturer's instructions. cDNA-synthesis and qPCR were performed exactly as described previously (31). The quantities of mRNA were normalized to $\alpha$-tubulin mRNA. Primers were designed with the aid of Invitrogen's OligoPerfect Designer and were obtained from Invitrogen Life Technologies (Darmstadt, Germany). Primer-downstream (DS) and upstream (US) sequences, the size of amplified DNA fragments in base pairs (bp) and the optimized annealing temperatures (AT) are listed in Table I.

Protein preparation and immunoblot analyses. The cells were seeded at a density of $5 \times 10^{5}$ cells/well $/ 3 \mathrm{ml}$ in a six-well plate and incubated for $24 \mathrm{~h}$. Following incubation with IL-1 $\beta$ for a further $24 \mathrm{~h}$, the cells were harvested and suspended in lysis buffer, which contained $50 \mathrm{mM}$ Tris- $\mathrm{HCl}(\mathrm{pH} 7.5)$, $100 \mathrm{mM} \mathrm{NaCl}, 5 \mathrm{mM}$ EDTA, $0.5 \%$ Triton X-100, 10\% glycerol, $10 \mathrm{mM} \mathrm{K} \mathrm{HPO}_{4}, 0.5 \%$ NP-40, $1 \mathrm{mM}$ phenylmethanesulfonyl 


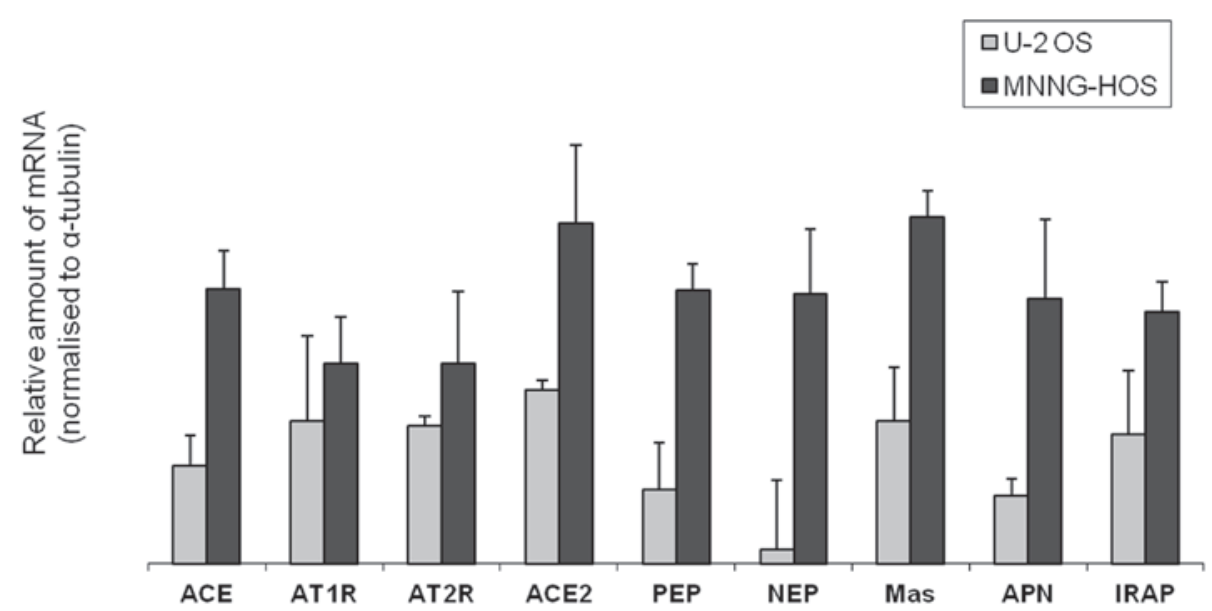

Figure 1. Detection of the mRNA expression of essential components of the classical (ACE, AT1R) or alternative (ACE2, AT2R, PEP, NEP, Mas, APN, IRAP) RAS axes in the osteosarcoma cell lines U-2 OS and MNNG-HOS. ACE, angiotensin-converting enzyme; ATR1, angiotensin II type 1 receptor; RAS, renin-angiotensin-system; PEP, prolyl-endopeptidase; NEP, neutral endopeptidase 24.11; APN, alanyl-aminopeptidase; IRAP, insulin-regulated aminopeptidase.

fluoride (Roche Diagnostics, Mannheim, Germany), $1 \mathrm{mM}$ sodium vanadate, $0.5 \%$ desoxycholate, $20 \mathrm{mM} \mathrm{NaF}, 20 \mathrm{mM}$ glycerol-2-phosphate and a protease inhibitor cocktail (all from Sigma, Heidelberg, Germany). Following an incubation period of $20 \mathrm{~min}$ on ice, the lysates were centrifuged at $15,000 \mathrm{x} \mathrm{g}$ for $30 \mathrm{~min}$ and the resulting supernatants were stored at $-80^{\circ} \mathrm{C}$ for further analysis. A total of $22 \mu \mathrm{g}$ protein in a final volume of $20 \mu 1$ 1x Laemmli-buffer (Bio-Rad, Hercules, CA, USA) were separated by SDS-PAGE and transferred to polyvinylidene fluoride membranes (Millipore, Bedford, MA, USA). Following blocking with $1 \mathrm{X}$ Roti $^{\circledR}$ Block (Carl Roth GmbH \& Co. KG, Karlsruhe, Germany) the membranes were incubated with rabbit anti-Mas (LS-B3564; LifeSpan Biosciences, Inc., Seattle, WA, USA), at a dilution of 1:2,000 in phosphate-buffered saline (PBS)/5\% skimmed milk/0.03\% $\mathrm{NaN}_{3}$ (Carl Roth $\mathrm{GmbH} \&$ KG, Karlsruhe, Germany; Merck, Darmstadt, Germany) or goat anti-actin (I-19, SC-1616; Santa Cruz Biotechnology, Inc., Heidelberg, Germany), at a dilution of 1:500 in Tris-buffered saline with Tween 20 (TBST)/5\% bovine serum albumin/ $0.03 \%$ $\mathrm{NaN} 3$ (fraction $\mathrm{V}$; Carl Roth $\mathrm{GmbH} \& \mathrm{KG}$ ) overnight at $4^{\circ} \mathrm{C}$. This was followed by incubation with horseradish peroxidase-conjugated secondary antibodies: Anti-rabbit immunoglobulin (Ig) G 1:5,000 or anti-goat IgG 1:10,000 (purchased from Cell Signaling Technology, Inc., Frankfurt am Main, Germany) in a 1x Roti ${ }^{\circledR}$ Block. For detection by enhanced chemiluminescence, Super Signal West Dura Extended Duration Substrate (Pierce Biotechnology, Inc., Rockford, IL, USA), was used. The protein expression was quantified using Alpha Ease FC software (Alpha Imager System; Alpha Innotech Corp., San Leandro, CA, USA).

Proliferation assay. To investigate the effect of different agents on the proliferation of U-2 OS or MNNG-HOS cells, the CyQUANT ${ }^{\circledR}$ NF Cell Proliferation Assay kit (Invitrogen Life Technologies) was used according to the manufacturer's instructions. Osteosarcoma cells were seeded into 96-well plates (Greiner Bio-One, Frickenhausen, Germany) at a density of $1 \times 10^{4}$ cells/well/200 $\mu 1$ medium.

Migration assay. To investigate the potential effects on cell migration, the Cultrex ${ }^{\circledR}-24$ Well Cell Migration Assay (AMS
Biotechnology (Europe) Ltd., Abingdon, Oxfordshire, UK) was used. The assay was performed according to the manufacturer's instructions. The principle of the assay is based on a simplified Boyden chamber design with an $8-\mu$ m polyethylene terephthalate (PET) membrane. Detection of cell invasion was quantified using Calcein AM.

siRNA-mediated gene knockdown. To study the effect of Mas gene silencing, cells were seeded into six-well plates at a density of $5 \times 10^{5}$ cells/well/3 $\mathrm{ml}$ and cultured for $24 \mathrm{~h}$, respectively. For gene silencing h-MAS1-small interfering (si)RNA, (SI03068898; Qiagen, Hilden, Germany), control-siRNA (SI1027280; Qiagen) and SiLentFect lipid reagent (Bio-Rad) were used, following the instructions by Bio-Rad. A total of $24 \mathrm{~h}$ following transfection, the cells were used for the experiments (the migration and proliferation assays). Knockdown of Mas expression was confirmed by qPCR in separate aliquots.

Statistical analysis. Mann-Whitney U tests were applied in the case of $n \geq 4$. Non-parametric data were illustrated as boxplots with medians, quartiles and an interquartile range $(\mathrm{IQR}) \pm 1.5 \times \mathrm{IQR}$. Data are expressed as the median \pm quartile 1 and 3 (Q1 and Q3). P<0.05 was considered to indicate a statistically significant difference.

\section{Results}

mRNA expression of essential components of the classical axes in osteocarcinoma cell lines. The classical RAS axis has been implicated in the development and metastasis of various tumor types and cohort studies revealed that ACE inhibitors reduce the risk of tumors $(26,27)$. Less is known about the expression and function of the alternative ACE2/Ang(1-7)/Mas axis in osteosarcoma. Thus, the present study aimed to determine the basic and cytokine-dependent expression of RAS components in U-2 OS and MNNG-HOS cells. As revealed in Fig. 1, the cell lines demonstrated mRNA expression for the proteolytic enzymes ACE, ACE2, membrane alanyl-aminopeptidase (APN), neutral endopeptidase 24.11 (NEP) and prolyl-endopeptidase (PEP), as well as for the different 
U-2 OS
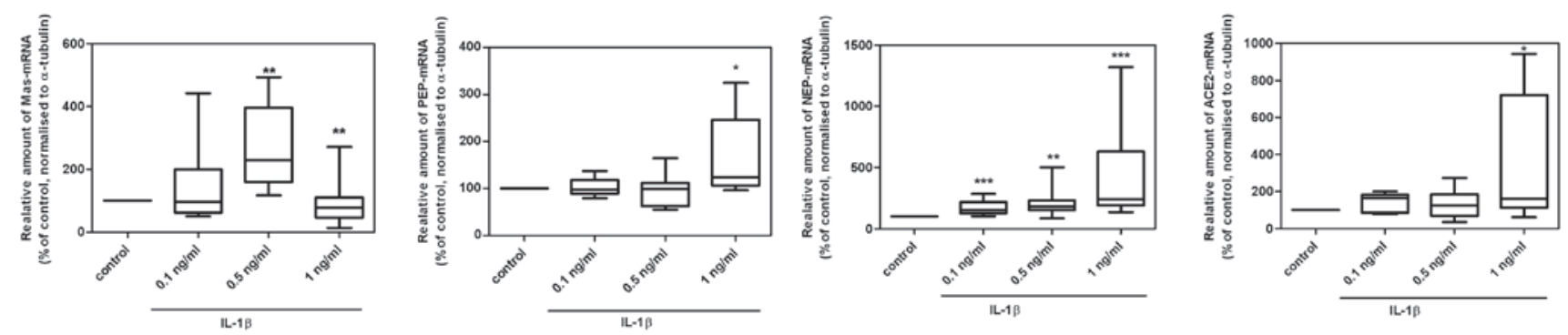

\section{MNNG-HOS}
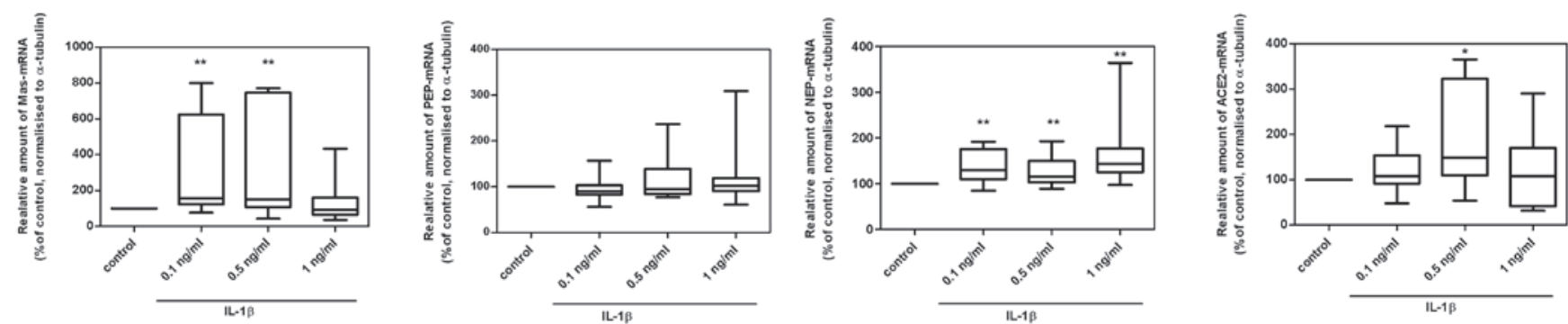

Figure 2. Effect of IL-1 $\beta$ on the mRNA expression levels of RAS components in U2-OS and MNNG-HOS cells. IL-1 $\beta$ provoked a dose-dependent increase in the mRNA expression of Mas, ACE2, PEP, and NEP following $24 \mathrm{~h}$. Data are expressed as the median $\pm \mathrm{Q} 1$ and $\mathrm{Q} 3 ; \mathrm{n}=6$; ${ }^{*} \mathrm{P}<0.05,{ }^{* *} \mathrm{P}<0.01$ and ${ }^{* * * *} \mathrm{P}<0.001$ compared with the control. IL-1 $\beta$, interleukin-1 $\beta$; RAS, renin-angiotensin-system; ACE, angiotensin-converting enzyme; PEP, prolyl-endopeptidase; NEP, neutral endopeptidase 24.11; Q, quartile.

U-2 OS MNNG-HOS
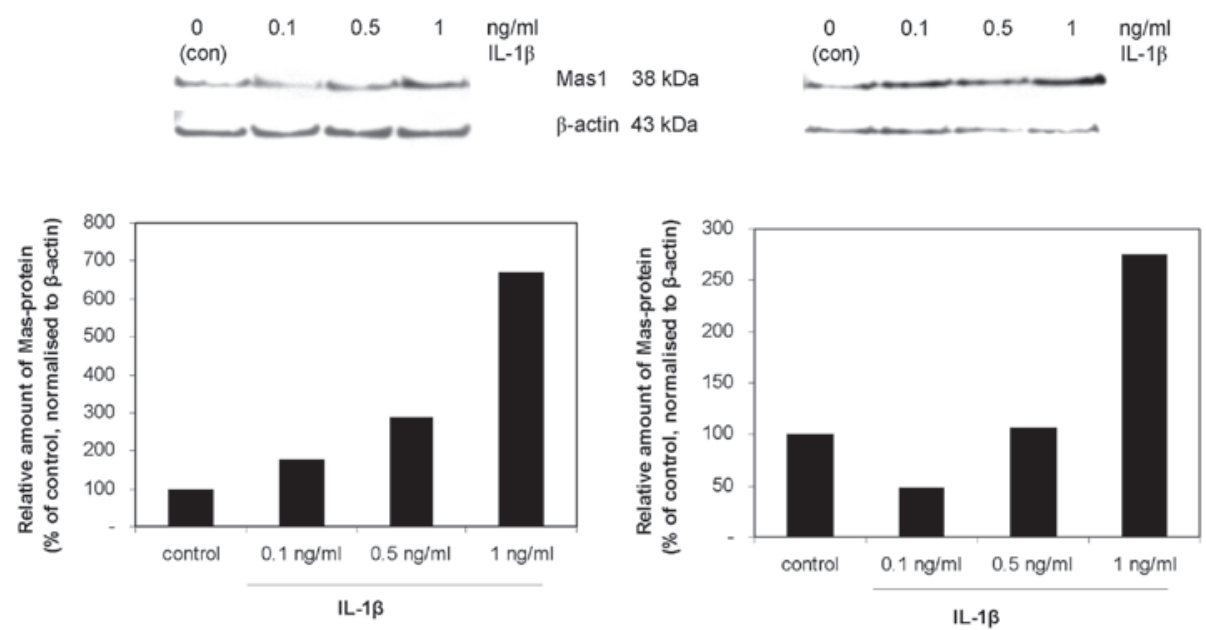

Figure 3. Effect of IL-1 $\beta$ on the amounts of MAS protein in U-2 OS and MNNG-HOS cells. Exposure of cells to various concentrations of IL-1 $\beta$ for $24 \mathrm{~h}$ provoked a dose-dependent increase in the protein expression of Mas. IL-1 $\beta$, interleukin-1 $\beta$.

angiotensin receptor subtypes, AT1R, AT2R, Mas and AT4R; the latter is also known as insulin-regulated aminopeptidase (IRAP). MNNG-HOS cells exhibited higher expression levels of all RAS components investigated.

Effect of IL-1 $\beta$ on the mRNA expression levels of RAS components in osteocarcinoma cell lines. In response to IL-1 $\beta$, a significant increase in the mRNA expression levels of the Ang(1-7) receptor, Mas and the Ang(1-7)-generating enzymes NEP and ACE2 was observed in both U-2 OS and MNNG-HOS cells. However, PEP-mRNA expression levels increased in U-2 OS cells only (Fig. 2). The dose-dependent increase of Mas expression in response to IL-1 $\beta$ was confirmed at the protein level in U-2 OS and MNNG-HOS cells (Fig. 3). Furthermore, a similar increase of Mas expression was observed in response to $\mathrm{TNF} \alpha$ (data not shown), suggesting the involvement of $\mathrm{NF}-\mathrm{\kappa B}$ signalling in Mas induction.

Effects of IL-1 $\beta$-dependent increase of Mas expression on cell proliferation and migration. Next, the question whether the IL-1 $\beta$-dependent increase of Mas expression had functional implications was addressed by assessing cell proliferation and migration. As demonstrated in Fig. 4A, IL-1 $\beta$ provoked a moderate but significant reduction in proliferation of the two cell lines (U-2 OS: $90 \%$ of control, $\mathrm{P}=0.027$; MNNG-HOS: $88 \%$ of control, $\mathrm{P}=0.026$ ) in parallel with an observed induction 
A

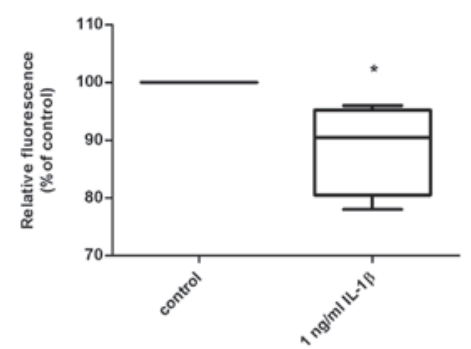

B

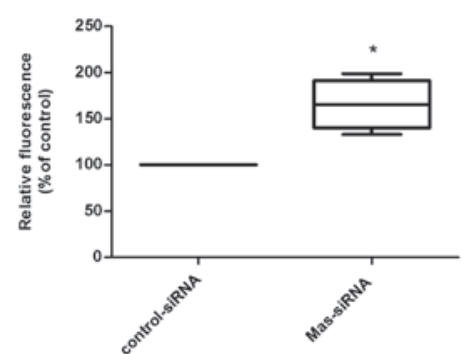

MNNG-HOS
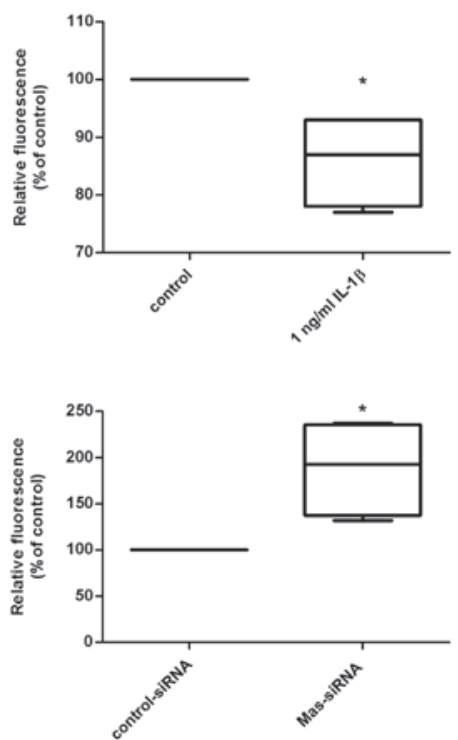

Figure 4. Effects of IL-1 $\beta$ and Mas expression on proliferation of osteosarcoma cells. (A) IL-1 $\beta$ reduced the proliferative ability and (B) siRNA-mediated knockdown of Mas provoked an increase in the proliferation of U-2 OS and MNNG-HOS cells. Data are expressed as the median \pm Q1 and Q3; $\mathrm{n}=4$; " $\mathrm{P}<0.05$, compared with the control. IL-1 $\beta$, interleukin-1 $\beta$; Q, quartile.

$\mathrm{U}-2$ OS

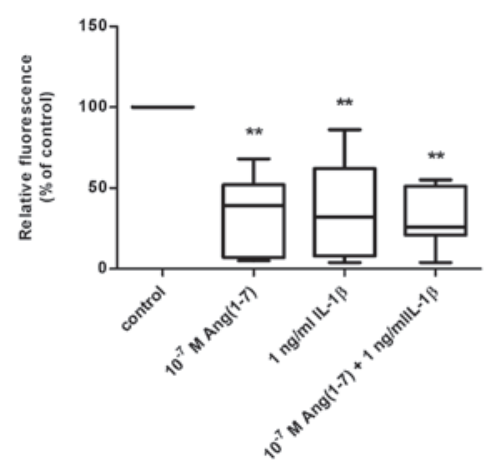

MNNG-HOS

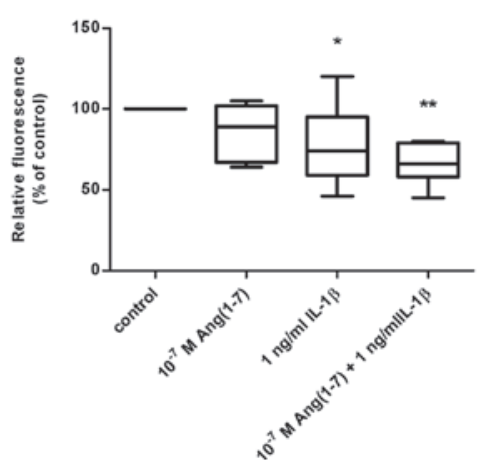

Figure 5. Effects of IL-1 $\beta$ and Ang(1-7) alone and in combination on the migration of U-2 OS and MNNG-HOS cells. IL-1 $\beta$ diminished the migration of the U-2 OS and MNNG-HOS cells, whereas Ang(1-7) inhibited the migration of U-2 OS cells only. IL-1 $\beta$ applied together with Ang(1-7) led to a significant decrease in the migration of both cell lines. Data are expressed as the median $\pm \mathrm{Q} 1$ and $\mathrm{Q} 3 ; \mathrm{n}=4$; ${ }^{\mathrm{P}} \mathrm{P}<0.05,{ }^{* *} \mathrm{P}<0.01$, compared with the control. IL-1 $\beta$, interleukin-1 $\beta$; $\mathrm{Q}$, quartile; Ang, angiotensin.

of Mas expression. To further substantiate a possible linkage between Mas expression and osteosarcoma cell proliferation, siRNA-mediated knockdown of Mas was performed. Fig. 4B demonstrates that the decrease in Mas expression lead to increased proliferation of U-2 OS (1.7-fold; $\mathrm{P}<0.03)$ and MNNG-HOS cells (1.9-fold; $\mathrm{P}=0.03$ ).

Interleukin-1 $\beta$ inhibited the migration of U-2 OS and MNNG-HOS cells (Fig. 5). This effect was more prominent in $\mathrm{U}-2$ OS $(40 \%$ of control; $\mathrm{P}<0.01)$ as compared with the MNNG-HOS cell line ( $80 \%$ of control; $\mathrm{P}=0.024$ ). In support of the hypothesis that these effects on migration are due to altered Mas expression, a similar inhibitory effect on cell migration was observed in response to the administration of the natural agonistic ligand for the Mas receptor, Ang(1-7). As demonstrated in Fig. 5, Ang(1-7) reduced cell migration to $48 \%$ in $\mathrm{U}-2$ OS cells $(\mathrm{P}<0.01)$, whereas MNNG-HOS cells revealed a tendency towards reduced migration only.
However, Ang(1-7) applied together with IL-1 $\beta$ induced a highly significant reduction of migration also in the MNNG-HOS cell line ( $62 \%$ of control; $\mathrm{P}<0.01)$. As expected, the siRNA-mediated knockdown of Mas led to an increase in cell migration which appeared to be more pronounced in U-2 OS cells (1.4-fold) compared with MNNG-HOS cells (1.1-fold).

\section{Discussion}

The aim of the present study was to elucidate the expression and possible functional relevance of the alternative ACE2/Ang(1-7)/Mas RAS axis in osteosarcoma cells. The results of this study demonstrated that all essential components of this axis, including Ang(1-7)-generating proteases and the putative Ang(1-7) receptor, Mas, are expressed in U-2 OS and MNNG-HOS osteosarcoma cell lines. 
The Mas gene was first cloned in 1986 from carcinoma cells (28), and was identified to provoke the development and growth of tumors upon transfer into nude mice. Accordingly, Mas was regarded initially as a proto-oncogene. The anti-proliferative activity of Mas transgene expression or the preferred Mas ligand, Ang (1-7) was revealed in later studies (29). The results of the present study demonstrated that in the osteosarcoma cell lines utilized, there was an IL-1 $\beta$-dependent increase in Mas expression, which was associated with decreased cell proliferation. By contrast, the opposite effect was observed in response to a siRNA-mediated knockdown of Mas. Although these findings are consistent with the proposed anti-proliferative effects of Mas, it should be mentioned that there is no direct evidence supporting the causality between IL-1 $\beta$-dependent Mas induction and diminished proliferation of osteosarcoma.

Previous studies demonstrated that blocking of IL-1 $\beta$ activity, by means of IL-1 receptor antagonist (IL-1Ra) together with administration of the green tea-derived epigallocatechin gallate, results in effective downregulation of pro-inflammatory and pro-angiogenic cytokines, including IL-6, IL-8 and VEGF in U-2 OS cells (30). This evidence implicated a role of IL-1 $\beta$ in tumor progression and immune escape mechanisms, and simultaneously suggested that IL-1 $\beta$-dependent Mas induction may act as compensatory and growth-limiting mechanisms. This indicated that the cytokine/Mas function in osteosarcoma is highly complex. In parallel to increasing Mas expression levels, IL-1 $\beta$ provoked a substantial increase in ACE2 expression. Therefore, it is possible to hypothesize, that increased ACE2 expression results in higher levels of Ang(1-7), which would then be able to bind to the more abundant Mas receptor with ease. This would represent a shift from the detrimental classical ACE/AngII/AT1R axis to the counter-acting and, possibly beneficial, ACE2/Ang(1-7)/Mas axis of the RAS. Such a shift from classical to alternative RAS axes would also be facilitated by the observed increase in the expression of NEP.

By contrast to the tumor-promoting activity of AngII/AT1R described above, Ang(1-7) has been demonstrated to inhibit migration and invasion of lung carcinoma cells and lung cancer $(15,16)$. Similar effects were observed in response to ACE2 overexpression (17,18).

In summary, the present study demonstrated the expression of essential components of classical and alternative RAS axes in osteosarcoma cell lines. Activation of the ACE2/Ang(1-7)/Mas axis compromised osteosarcoma growth and migration, and may therefore represent a promising therapeutic option. Furthermore, it was demonstrated that (pro-inflammatory) cytokines are capable of modulating the expression/activity of RAS axes, and in particular, that of the ACE2/Ang(1-7)/Mas axis, which implicates the existence of a number of more complex humoral networks that are involved in net tumor growth, progression and metastasis. Additional studies are required to further elucidate this complexity to translate these results into clinical applications.

\section{Acknowledgements}

The authors are grateful to Manja Möller and Ines Schultz for excellent technical assistance.

\section{References}

1. Peach MJ: Renin-angiotensin system: biochemistry and mechanisms of action. Physiol Rev 57: 313-370, 1977.

2. Deshayes F and Nahmias C: Angiotensin receptors: a new role in cancer? Trends Endocrinol Metab 16: 293-299, 2005.

3. Tamarat R, Silvestre JS, Durie M and Levy BI: Angiotensin II angiogenic effect in vivo involves vascular endothelial growth factor- and inflammation-related pathways. Lab Invest 82: 747-756, 2002.

4. Pupilli C, Lasagni L, Romagnani P, Bellini F, Mannelli M, Misciglia N, Mavilia C, Vellei U, Villari D and Serio M: Angiotensin II stimulates the synthesis and secretion of vascular permeability factor/vascular endothelial growth factor in human mesangial cells. J Am Soc Nephrol 10: 245-255, 1999.

5. Otani A, Takagi H, Oh H, Koyama S and Honda Y: Angiotensin II induces expression of the Tie2 receptor ligand, angiopoietin-2, in bovine retinal endothelial cells. Diabetes 50: 867-875, 2001.

6. Fujita M, Hayashi I, Yamashina S, Itoman M and Majima M: Blockade of angiotensin ATla receptor signaling reduces tumor growth, angiogenesis, and metastasis. Biochem Biophys Res Commun 294: 441-447, 2002.

7. Suganuma T, Ino K, Shibata K, Kajiyama H, Nagasaka T, Mizutani S and Kikkawa F: Functional expression of the angiotensin II type 1 receptor in human ovarian carcinoma cells and its blockade therapy resulting in suppression of tumor invasion, angiogenesis, and peritoneal dissemination. Clin Cancer Res 11: 2686-2694, 2005.

8. Yasumatsu R, Nakashima T, Masuda M, Ito A, Kuratomi Y, Nakagawa $T$ and Komune $S$ : Effects of the angiotensin-I converting enzyme inhibitor perindopril on tumor growth and angiogenesis in head and neck squamous cell carcinoma cells. J Cancer Res Clin Oncol 130: 567-573, 2004.

9. Neo JH, Malcontenti-Wilson C, Muralidharan V and Christophi C: Effect of ACE inhibitors and angiotensin II receptor antagonists in a mouse model of colorectal cancer liver metastases. J Gastroenterol Hepatol 22: 577-584, 2007.

10. Ebert MP, Lendeckel U, Westphal S, Dierkes J, Glas J, Folwaczny C, Roessner A, Stolte M, Malfertheiner P and Röcken C: The angiotensin I-converting enzyme gene insertion/deletion polymorphism is linked to early gastric cancer. Cancer Epidemiol Biomarkers Prev 14: 2987-2389, 2005.

11. Röcken C, Lendeckel U, Dierkes J, Westphal S, Carl-McGrath S, Peters B, Krüger S, Malfertheiner P, Roessner A and Ebert MP: The number of lymph node metastases in gastric cancer correlates with the angiotensin I-converting enzyme gene insertion/deletion polymorphism. Clin Cancer Res 11: 2526-2530, 2005.

12. Röcken C, Röhl FW, Diebler E, Lendeckel U, Pross M, Carl-McGrath S and Ebert MP: The angiotensin II/angiotensin II receptor system correlates with nodal spread in intestinal type gastric cancer. Cancer Epidemiol Biomarkers Prev 16: 1206-1212, 2007.

13. Wasa J, Sugiura H, Kozawa E, Kohyama K, Yamada K and Taguchi O: The tumor suppressive effect of angiotensin II type 1 receptor antagonist in a murine osteosarcoma model. Anticancer Res 31: 123-127, 2011.

14. Santos RA, Simoes e Silva AC, Maric C, Silva DM, Machado RP, de Buhr I, Heringer-Walther S, Pinheiro SV, Lopes MT, Bader M, Mendes EP, Lemos VS, Campagnole-Santos MJ, Schultheiss HP, Speth R and Walther T: Angiotensin-(1-7) is an endogenous ligand for the $\mathrm{G}$ protein-coupled receptor Mas. Proc Natl Acad Sci USA 100: 8258-8263, 2003.

15. Ni L, Feng Y, Wan H, Ma Q, Fan L, Qian Y, Li Q, Xiang Y and Gao B: Angiotensin-(1-7) inhibits the migration and invasion of A549 human lung adenocarcinoma cells through inactivation of the PI3K/Akt and MAPK signaling pathways. Oncol Rep 27: 783-790, 2012.

16. Gallagher PE and Tallant EA: Inhibition of human lung cancer cell growth by angiotensin-(1-7). Carcinogenesis 25: 2045-2052, 2004.

17. Feng Y, Ni L, Wan H, Fan L, Fei X, Ma Q, Gao B, Xiang Y, Che J and Li Q: Overexpression of ACE2 produces antitumor effects via inhibition of angiogenesis and tumor cell invasion in vivo and in vitro. Oncol Rep 26: 1157-1164, 2011.

18. Qian YR, Guo Y, Wan HY, Fan L, Feng Y, Ni L, Xiang Y and Li QY: Angiotensin-converting enzyme 2 attenuates the metastasis of non-small cell lung cancer through inhibition of epithelial-mesenchymal transition. Oncol Rep 29: 2408-2414, 2013. 
19. Warburg O: On the origin of cancer cells. Science 123: 309-314, 1956.

20. $\mathrm{Wu} \mathrm{W}$ and Zhao S: Metabolic changes in cancer: beyond the Warburg effect. Acta Biochim Biophys Sin (Shanghai) 45: 18-26, 2013.

21. Cifuentes M, García MA, Arrabal PM, Martínez F, Yañez MJ, Jara N, Weil B, Domínguez D, Medina RA and Nualart F: Insulin regulates GLUT1-mediated glucose transport in MG-63 human osteosarcoma cells. J Cell Physiol 226: 1425-1432, 2011.

22. Costelloe CM, Macapinlac HA, Madewell JE, Fitzgerald NE, Mawlawi OR, Rohren EM, Raymond AK, Lewis VO, Anderson PM, Bassett RL Jr, Harrell RK and Marom EM: 18F-FDG PET/CT as an indicator of progression-free and overall survival in osteosarcoma. J Nucl Med 50: 340-347, 2009.

23. Franzius C, Bielack S, Flege S, Sciuk J, Jürgens $\mathrm{H}$ and Schober O: Prognostic significance of (18)F-FDG and (99m)Tc-methylene diphosphonate uptake in primary osteosarcoma. J Nucl Med 43 : 1012-1017, 2002.

24. Liu C, Lv XH, Li HX, Cao X, Zhang F, Wang L, Yu M and Yang JK: Angiotensin-(1-7) suppresses oxidative stress and improves glucose uptake via Mas receptor in adipocytes. Acta Diabetol 49: 291-299, 2012

25. Giani JF, Mayer MA, Muñoz MC, Silberman EA, Höcht C, Taira CA, Gironacci MM, Turyn D and Dominici FP: Chronic infusion of angiotensin-(1-7) improves insulin resistance and hypertension induced by a high-fructose diet in rats. Am J Physiol Endocrinol Metab 296: E262-E271, 2009.
26. Lever AF, Hole DJ, Gillis CR, McCallum IR, McInnes GT, MacKinnon PL, Meredith PA, Murray LS, Reid JL and Robertson JW: Do inhibitors of angiotensin-I-converting enzyme protect against risk of cancer? Lancet 352: 179-184, 1998.

27. Friis S, Sørensen HT, Mellemkjaer L, McLaughlin JK, Nielsen GL, Blot WJ and Olsen JH: Angiotensin-converting enzyme inhibitors and the risk of cancer: a population-based cohort study in Denmark. Cancer 92: 2462-2470, 2001.

28. Young D, Waitches G, Birchmeier C, Fasano O and Wigler M Isolation and characterization of a new cellular oncogene encoding a protein with multiple potential transmembrane domains. Cell 45: 711-719, 1986.

29. Alenina N, Xu P, Rentzsch B, Patkin EL and Bader M: Genetically altered animal models for Mas and angiotensin-(1-7). Exp Physiol 93: 528-537, 2008.

30. Hönicke A-S, Ender SA and Radons J: Combined administration of EGCG and IL-1 receptor antagonist efficiently downregulates IL-1-induced tumorigenic factors in U-2 OS human osteosarcoma cells. Int J Oncol 41: 753-758, 2012.

31. Chilukotia RK, Mostertz J, Bukowska A, Aderkast C, Felix SB, Busch M, Völker U, Goette A, Wolke C, Homuth G and Lendeckel U: Effects of irbesartan on gene expression revealed by transcriptome analysis of left atrial tissue in a porcine model of acute rapid pacing in vivo. Int J Cardiol 168: 2100-2108, 2013. 